\title{
Is the Quality of Generic Drugs Cause for Concern?
}

\author{
Daniel A. Hussar, PhD
}

Hussar's Viewpoint

T

he short answer to the question posed in the title is "yes"! As a pharmacist, I am often asked whether generic drug products are as effective and safe as, and equivalent to, higher-cost brand-name products. Until recently, I have confidently responded that individuals can be assured of the effectiveness, safety, and quality of generic products and that the U.S. Food and Drug Administration (FDA) is the most thorough and effective agency in the world with respect to the regulation, approval, and safety of drug products. However, recent events and information are great cause for concern. I continue to believe that the FDA is the best agency in the world in regulating medications, but it is not effective and thorough enough to provide assurance of the quality and safety of the drug supply that we should be able to expect.

\section{The Drug Supply}

Generic products are used in dispensing as many as $90 \%$ of prescriptions in the United States. To reduce the costs of labor and materials, most pharmaceutical companies use ingredients and manufacturing facilities in other countries, primarily China and India. Over the past 2 years, there has been extensive publicity and numerous FDA updates regarding carcinogenic contaminants (nitrosamines, e.g., N-nitrosodimethylamine [NDMA]) in many generic forms of valsartan and certain other angiotensin II receptor blocker formulations made in other countries. Fortunately, the risk of harm from these contaminants appears to be extremely small. A press release from the FDA on December 5, 2019, includes the statement that "a person taking a drug that contains NDMA at or below the acceptable daily intake limit every day for 70 years is not expected to have an increased risk of cancer." The statements of the FDA are intended to be reassuring; however, they do not address questions such as the following:

- Why are any of these contaminants present in any amount in the generic products in which they have been identified?

- Why have drug products containing contaminants initially escaped identification and been widely distributed and used in the United States before being recalled?

\section{J Manag Care Spec Pharm. 2020;26(5):597-99}

Copyright $\odot 2020$, Academy of Managed Care Pharmacy. All rights reserved.
- Now that certain generic products have been identified as containing contaminants and have been recalled, can the public be assured that other products they are taking do not contain these contaminants or are not otherwise adulterated?

- To what extent might the risk of cancer be increased in patients who have already taken the recalled products containing NDMA in greater than the "acceptable" limit for an extended period of time?

- To what extent might the risk of cancer be increased in patients who are taking a drug product that contains NDMA in an amount below the "acceptable" limit, and who are also consuming other products (identified by the FDA to include water, cured and grilled meats, dairy products, and vegetables) that contain small ("acceptable") amounts of nitrosamines?

When the Government Accountability Office last examined the number of the FDA's foreign inspections in 2016, it estimated that the FDA had never inspected nearly 1,000 of the almost 3,000 facilities in other countries that make and export drug ingredients to the United States. ${ }^{2}$ Some companies have multiple manufacturing facilities between which certain operations are transferred, thereby creating an additional issue analogous to the "whack-a-mole" carnival game.

A Bloomberg Businessweek article provides a detailed report that quotes a former FDA medical officer, "Valsartan is just the one we caught. Who knows how many more are out there?"3 The list is rapidly growing. Certain losartan and irbesartan formulations have been identified as containing nitrosamine contaminants. There have been many recalls of ranitidine products because of concerns about these nitrosamines, although there are additional questions as to whether the risk of the presence of these agents are also related to stability/degradation issues of ranitidine.

Fortunately, there are readily available, clinically equivalent alternatives to valsartan and ranitidine. However, the same situation does not exist with metformin, which has unique properties among the antidiabetic drugs and is the most commonly recommended initial oral therapy for patients with diabetes. The previously mentioned FDA statement of December 5, 2019, notes that some metformin products marketed in other countries have been reported to have low levels of NDMA. On February 3, 2020, the FDA posted laboratory testing results for NDMA levels in metformin products. ${ }^{4}$ The levels determined in 
the products tested range from "not detectable" to "low" (i.e., acceptable levels). It is further noted that the "FDA has not recommended metformin recalls in the U.S."

In addition to the presence of contaminants, there are numerous other reasons for which a generic product may be adulterated or not be equivalent to the brand-name product with the same medication. The most recent FDA Watch List includes tacrolimus capsules, for which the potential issue is "therapeutic inequivalence," and it is noted that the FDA is evaluating the need for regulatory action. ${ }^{5}$ I have not yet learned the specifics of this concern, but if the possible inequivalence is a reduction in potency, there are very serious implications for patients who have received organ transplants who would be more vulnerable to rejection of the transplanted organ because of inadequate immunosuppression.

\section{Bottle of Lies}

Katherine Eban's book, Bottle of Lies: The Inside Story of the Generic Drug Boom exposes the greed, fraud, and arrogance of certain individuals and companies in the generic drug industry. ${ }^{6}$ The book is alarming and compelling. In addition to the "villains" identified in the book, there are also "heroes" who include whistleblowers and certain FDA inspectors who did the right things while incurring personal risk, as well as certain FDA officials who encountered resistance in imposing warnings and penalties.

Which generic companies and drug products can be trusted? The answer for the vast majority of patients, health professionals, and public health advocates is "We don't know!"

\section{Recommendations}

The financial incentives for companies to use cheaper materials and labor in countries such as China and India have begun to expose the FDA's limitations and shortcomings in ensuring the quality and safety of drug products made in these countries. The present situation is unsafe and unacceptable and the following recommendations are provided:

1. Companies that sell and distribute drug products in the United States must have facilities in this country in which they can ensure the quality and safety of drug products and active pharmaceutical ingredients, regardless of the country of origin of the product. Products that are imported from other countries should not be placed in channels of distribution until after they are appropriately tested and found to be in compliance with FDA standards and regulations. There should be severe penalties for companies that fail to comply with standards and allow defective and unsafe products to reach the marketplace.

2. The FDA cannot, and should not, be expected to police and inspect all drug manufacturing facilities throughout the world that export drug products to the United States. Many companies in other countries that export drug products to the United States have never been inspected by the FDA and, of those that have been inspected, the inspections have often been scheduled and planned, rather than being unannounced. The FDA inspections of these companies/facilities must be unannounced.

3. The FDA must be more transparent. Some of their statements are vague and lacking in specifics. Under current regulations, the FDA may be prevented from disclosing the manufacturing location of a medication/product because it is considered commercial confidential information (not releasable). Such regulations should be rescinded, particularly at a time when carcinogenic contaminants are being identified. Secrecy increases skepticism and distrust. If the FDA cannot provide such information, and drug companies/suppliers will not, then one alternative is to not use those products.

It is understandable that the FDA does not want the public to be alarmed about the quality and safety of generic drug products and wants the public to be confident that the FDA is taking sufficient steps to protect the integrity of the drug supply. However, not enough is being done, and the FDA should discontinue the pretense that everything possible is being done to protect the quality and safety of medications. We must not wait for additional preventable drug-related tragedies or acts of terrorism using the drug distribution system to occur before appropriate actions are taken.

4. Pharmaceutical companies should substantially reduce the cost of their brand-name drugs when their patents expire and generic products can be available. These products have been the source of extensive revenue and profits for the companies during the period in which there was patent-protected exclusivity of marketing, and they can continue to market them profitably, even at a substantially reduced price.

5. Individuals with expertise in developing and manufacturing drug products should consider starting companies in the United States that specialize in generic products. Because generic drug products account for almost $90 \%$ of the prescriptions, and the most commonly used of these drugs are relatively inexpensive, the additional cost of making the products in the United States should be an affordable expense for a high level of assurance in their quality and safety.

6. Specific information regarding the manufacturing locations of pharmaceutical products, as well as the documentation of quality, potency, and equivalency, must be readily available to prescribers, pharmacists, and patients. Prescribers and pharmacists must be more aware of and attentive to pertinent information needed to make informed decisions that will ensure the quality and safety of medications for their patients. 


\section{Author}

DANIEL A. HUSSAR, PhD, is Dean Emeritus and Remington Professor Emeritus, Philadelphia College of Pharmacy, University of the Sciences, Philadelphia, Pennsylvania, and is author/editor of The Pharmacist Activist.

AUTHOR CORRESPONDENCE: Daniel A. Hussar, PhD, can be contacted atdanandsue3@verizon.net.

\section{DISCLOSURES}

No funding supported the writing of this article. The author has nothing to disclose.

\section{REFERENCES}

1. U.S. Food and Drug Administration. FDA statement from Janet Woodcock, M.D., director of FDA's Center for Drug Evaluation and Research, on impurities found in diabetes drugs outside the U.S. December 5, 2019. Available at: https://www.fda.gov/news-events/press-announcements/statement-janetwoodcock-md-director-fdas-center-drug-evaluation-and-research-impurities-found. Accessed March 31, 2020.
2. U.S. Government Accountability Office. FDA has improved its Foreign Drug Inspection Program, but needs to assess the effectiveness and staffing of its foreign offices. Report to the Committee on Energy and Commerce. December 2016. Available at: https://www.gao.gov/assets/690/681689.pdf. Accessed March 31, 2020.

3. Edney A, Berfield S, Yu E. Carcinogens have infiltrated the generic drug supply in the U.S. Bloomberg Businessweek. September 12, 2019. Available at: https://www.bloomberg.com/news/features/2019-09-12/how-carcinogentainted-generic-drug-valsartan-got-past-the-fda. Accessed March 31, 2020.

4. U.S. Food and Drug Administration. FDA updates and press announcements on NDMA in metformin. Laboratory testing results for NDMA in metformin. February 3, 2020. Available at: https://www.fda.gov/drugs/ drug-safety-and-availability/fda-updates-and-press-announcements-ndmametformin. Accessed March 31, 2020.

5. U.S. Food and Drug Administration. FDA quarterly reports. JulySeptember 2019: Potential signals of serious risks/new safety information identified by the FDA Adverse Event Reporting System (FAERS). As of December 20, 2019. Available at: https://www.fda.gov/drugs/questions-andanswers-fdas-adverse-event-reporting-system-faers/july-september-2019-potential-signals-serious-risksnew-safety-information-identified-fda-adverse. Accessed March 31, 2020.

6. Eban K. Bottle of Lies: The Inside Story of the Generic Drug Boom. New York: HarperCollins Publishers; 2019. 